\title{
Measles Vaccination among Children (12 to 23 Months) in IDPs Settlements of Khartoum State, Sudan
}

\author{
Fatima Elshikh Elhadi ${ }^{1}$ and Ibrahim Awad Ibrahim²,
}

\author{
${ }^{1}$ Department of Public Health, Faculty of Applied Medical Sciences, King Khalid University Saudi Arabia \\ ${ }^{2}$ Department of Community and Family Medicine, Faculty of Medicine, Al-Baha University, Saudi Arabia
}

\begin{abstract}
Objectives: To assess the coverage rate of measles vaccine among children 12 to 23 months old and causes behind non-immunization in Internally Displaced Persons (IDPs) settlements.

Methods: A multistage cluster sampling, community-based, descriptive cross-sectional study was conducted in IDPs Settlements of Khartoum State, Sudan, in 2009. Questionnaires were collected from 210 children (12 to 23 months) old to determine the coverage rate and causes behind non-immunization with measles vaccine.

Results: Almost one quarter (24.8\%) of children was not vaccinated by measles and the coverage rate was $75.2 \%$; most of them had a vaccination card ( $86 \%$ ) which means a high documentation and verification of mothers answers and only $14 \%$ verified the immunization status of their children by memory. The major cause of none vaccination was because of the busyness of the mother to take her child for vaccination, which comprises $10 \%$ of the children, followed by $6.2 \%$ of children not vaccinated because their mothers give no reason for not vaccinating their children. There was evidence of a significant association $(P$-Value $=0.037$ ) between education level of the mothers' and numbers of children under five years in the family with the immunization of Measles.

Conclusion: Coverage of measles vaccination among children aged 12-23 months in IDPs settlements in Khartoum state was reasonably acceptable. The most common reasons for non-immunization were that the caretakers were busy to take their children for vaccination and being unaware of need to return for measles vaccine. Apply a health promotion program and use of different comprehensive interventions to convince mothers to complete measles immunization and increases coverage rate, also plan and implement an effective health education program to increase the awareness of mothers on the importance of measles vaccination.
\end{abstract}

Keywords: IDPs, Measles vaccine.

\section{INTRODUCTION}

Measles is a serious and highly contagious disease that spread easily through air [1]. It is among the most prevalent infections among children in developing countries. They cause a significant morbidity and mortality in endemic countries and it is one of the leading causes of death among young children [2]. Although, vaccination of children of these age groups is available and it is safe and cost effective to prevent the disease [2], still measles considered as a major causes of childhood mortality especially among displaced persons [3]. In 2007 there were 197,100 measles death globally nearly 540 death every day or 22 every hours [4]. Sudan is considered as one of the countries having measles infections as a public health problem. In Sudan measles is the third cause of infant mortality from all causes, and the first killer among the vaccine preventable disease [2]. The outcome of this study was to determine the coverage rate of measles vaccine and causes of non-immunization among children in the age group between 12-23 months in the study area. Although this age group of children is considered as a

*Address correspondence to this author at the Department of Community and Family Medicine, Faculty of Medicine, Al-Baha University, Saudi Arabia; Tel: 009667 7274111; Fax: 009667 7247272; E-mail: aljack123@yahoo.com target of intervention by different strategies to solve low vaccine coverage problem through acceleration campaign, and defaulters follow up by health centers vaccinators, but still low vaccination coverage of measles is recorded in the IDPs, which may indicates other reasons regarding utilization of vaccination service in the IDPs. This study was conducted to help in the formulation of policies and intervention programs based on evidences in order to improve the health situation of children and the health status of the population in all IDPs settlements in Khartoum State.

\section{METHODS}

This cross-sectional study was conducted during the period from May to October 2009 in IDPs settlements of Khartoum State, Sudan. Khartoum State has 6 IDPs settlements, which considered as the main sampling domains and a multistage sampling technique was used for this Survey. The primary sampling units (PSUs) were the quarters in the IDPs settlements. The selected quarters were divided to small clusters of 30 households forming the secondary sampling units (SSUs) from which one cluster was selected randomly. The Tertiary Sampling Units (TSUs) were the households. The sample size was calculated using (WHO) recommended "standard" coverage survey 
method, WHO/IVB/July 2009 desired level of precision estimate $( \pm 10 \%)$ with expected immunization coverage (70\%). the sample size was found to be 210 children. Number of 30-cluster sample was selected randomly. Number of children per cluster is 7 and the total sample size $=$ Number of children per cluster $x$ number of clusters $30 \times 7=210$ [5]. Within each IDPs settlements the PSUs were selected with probability proportional to size (PPS), the total clusters were 30 , which were selected randomly from SSUs (small clusters of 30 households). The TSUs (households) were selected systematically with random start from the listing in each sampled SSU. Within each household all children (1223 months) were included in the study. Data was collected using a structured questionnaire, which was purposely designed and formulated for this research. The participants' caretakers were interviewed directly (face to face) in order to collect health information on socio-demographic and economic factors of relevance to the households, which, consist of income, occupation and other information like the knowledge about measles vaccination, availability, and accessibility of services. This was administered by trained data collectors and trained female/male Community Health Workers, who had an experience as research assistants.

\section{Limitations of the Study and Measures to Minimize}

Although measures have been taken to reduce the feasible limitations of this study as much as possible, there were still some limitations in the following aspects; Selection bias has known effect on the validity of the study results. Failure to obtain information from a designated individual for any reason (absence or refusal to reply) was expected in this study especially incomplete response when immunization card requested. To control that enough sample was selected, enough explanation of the benefits and importance of the immunization card were given. In this study recall bias was expected particularly when asking for measles immunization recall. In order to avoid recall bias, we allowed the caretaker to use any documents to help them to recall. The interviewer asked leading questions and the interviewer ensured getting assistant from other family members while the subject was recalling. To avoid the measurements bias; a pretest of the questionnaires was carried out two weeks prior to the study date on 50 households. They were chosen randomly and they were comparable thus having similar characteristics with the study subjects, they were not included as study subjects during the actual study duration. The result was used in order to examine the practicability, and reliability of the questions. The study questionnaire was adjusted accordingly and makes the interviewer familiar with the questions.

\section{RESULTS}

1. The Coverage Rate of Measles Vaccine among Children (12-23) Months and the Use of the Strategies of Vaccination in the IDPS

Almost all children's caretakers (210 children) agreed to participate in the survey, but only $86 \%$ of them gave the immunization card at the time of the study and the remaining $14 \%$ verified their immunization status by memory. The total coverage rate of measles vaccination was $75.2 \%$. Most common strategies used for measles vaccination were shown in Figure 1 . On the other hand, $4.4 \%$ are vaccinated by mobile team and $1.3 \%$ by other sources, which are mainly acceleration campaign, or defaulter follows up vaccination team.

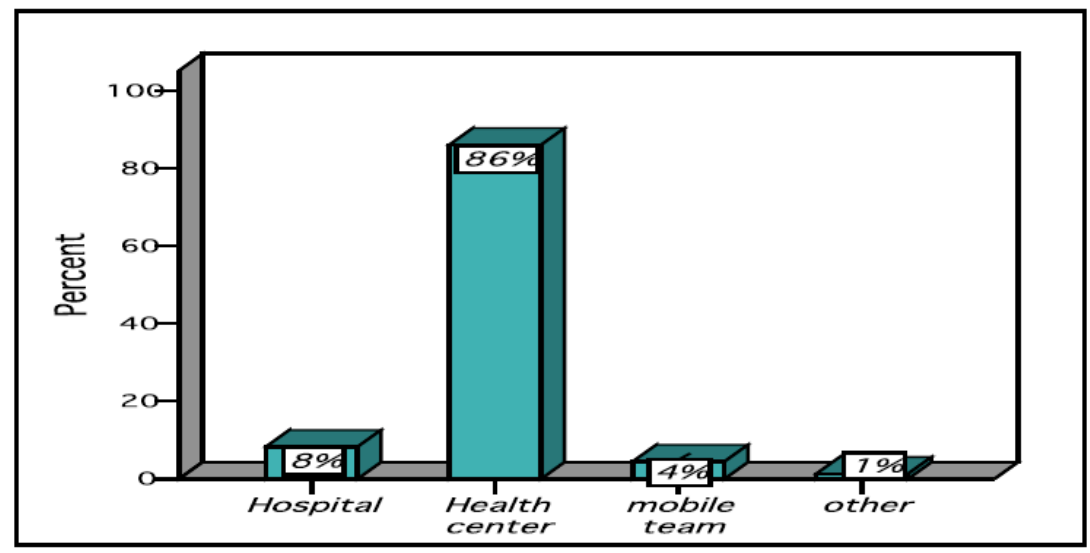

Figure 1: Shows percentage distribution of children 12 to 23 months old by the place they received measles vaccination in the IDPs camps, Khartoum state, Sudan, 2009 ( $N=210)$. 
2. The Reasons for Non-Immunization among Children (12-23) Months, Accessibility and Utilization of Measles Vaccination Services and Mothers' Knowledge about Measles Vaccination and their Attitude in IDPs Camps

The reasons for non-immunizations justified by caretakers were shown in Table 1. Concerning the accessibility of health centers, $67.1 \%$ of mothers live in distance less than $2 \mathrm{~km}$ from the health centers, while $25 \%$ live within the distance less than $5 \mathrm{~km}$, only $7.1 \%$ of mothers live within distance more than $5 \mathrm{~km}$. Considerable percentage of mothers $(5.8 \%)$ visited the health center for immunization and did not find vaccine because of different reasons, which were shown in Table 2. About $83 \%$ of mothers know the measles vaccination and $66 \%$ of them know the exact age of

Table 1: Frequency and Percentage Distribution of Children 12 to 23 Months Old by Reasons of Non-Immunization with the Measles Vaccine in the IDPs Camps, Khartoum State, Sudan, 2009 ( $N=52)$

\begin{tabular}{|c|c|c|}
\hline Reasons of Non-Immunization & Frequency & Percent \\
\hline The mother think that she has completed her child schedule of vaccination & 5 & 9.6 \\
\hline The mother think that her child has taken many vaccine and measles is the last one & 2 & 3.8 \\
\hline The mother's child was sick & 5 & 9.6 \\
\hline The mother return the child back to the vaccination site, but there was no vaccine available & 3 & 5.8 \\
\hline The mother did not find the vaccinator in the vaccination site & 1 & 1.9 \\
\hline The mother was busy to take her child for vaccination & 21 & 40.4 \\
\hline The child's father didn't allow the vaccination & 2 & 3.8 \\
\hline There was no reason & 13 & 25.0 \\
\hline Total & 52 & 100.0 \\
\hline
\end{tabular}

Table 2: Frequency and Percentage Distribution of Children 12 to 23 Months Old by Reasons of Not Obtain Measles Vaccination in the IDPs Camps, Khartoum State, Sudan, 2009 ( $N=53)$

\begin{tabular}{|l|c|c|}
\hline \multicolumn{1}{|c|}{ Reasons of Not Obtain Measles Vaccination } & Frequency & Percent \\
\hline \hline The vaccine was not available in the health center & 25 & 47.2 \\
\hline The health worker was not present at that time & 15 & 28.3 \\
\hline The measles vaccine scheduled certain days per week & 10 & 18.9 \\
\hline Others & 3 & 5.7 \\
\hline \multicolumn{1}{|c|}{ Total } & $\mathbf{5 3}$ & $\mathbf{1 0 0 . 0}$ \\
\hline
\end{tabular}

Table 3: Frequency and Percentage Distribution of Mothers by their Knowledge about the Measles Vaccination Age in the IDPs Camps, Khartoum State, Sudan, 2009 ( $N=210)$

\begin{tabular}{|l|c|c|}
\hline \multicolumn{1}{|c|}{ Knowledge of Mother about Measles Vaccination Age } & Frequency & Percent \\
\hline \hline Less than 9 months & 51 & 24.3 \\
\hline At 9 month & 139 & 66.2 \\
\hline Above 9 months & 13 & 6.2 \\
\hline Don't know & 7 & 3.3 \\
\hline \multicolumn{2}{r|}{ Total } & $\mathbf{2 1 0}$ \\
\hline
\end{tabular}

Table 4: Frequency and Percentage Distribution of the Mothers by Reasons of the Lack of Knowledge about the Importance of Measles Vaccination in the IDPs Camps, Khartoum State, Sudan, 2009 (N=27)

\begin{tabular}{|l|c|c|}
\hline \multicolumn{1}{|c|}{ Reasons of the Lack of Knowledge about the Importance of Measles Vaccination } & Frequency & Percent \\
\hline \hline Child will get sick & 1 & 3.7 \\
\hline Measles affect child if immunized or not & 7 & 25.9 \\
\hline My child became paralysis if take many injection & 6 & 22.2 \\
\hline Other $\quad$ Total & $\mathbf{7}$ & $\mathbf{2 7}$ \\
\hline
\end{tabular}


measles vaccination as shown in Table 3. More than three quarters of the mothers know the importance of measles vaccination (87.1\%) and $12.7 \%$ show different reasons for lack in the importance of measles vaccine as shown in Table 4.

\section{The Association between the Socio-} Demographic Characteristics of the Study Population and the Measles Vaccination

Concerning the association between the Sociodemographic characteristics of the study population and the Measles vaccination, with $\alpha=0.05$ and a $P$ value of $<0.05$, there was evidence of a significant association ( $P$-Value $=0.037$ ) between education level of the mothers' and the number of children under five in the family with immunization of Measles as shown in Tables 6 and 7. On the other hand, there was no evidence of significant association between children gender and age, mothers' age and child rank in the family as shown in Tables 5, 8, 9 and $\mathbf{1 0 .}$

Table 5: Chi-Square Test Showing the Association between Mothers' Age and Measles Vaccination in IDPs Camps, Khartoum State, Sudan, 2009

\begin{tabular}{|c|c|c|c|}
\hline \multirow{2}{*}{ Age of the Mother } & \multicolumn{2}{|c|}{ Immunization of Measles } & \multirow{2}{*}{ Total } \\
\cline { 2 - 3 } & Yes & No & \\
\hline \hline Less than 20 year & 13 & 10 & 23 \\
\hline 20-30 year & 100 & 31 & 131 \\
\hline Above 30 year & 45 & 11 & 56 \\
\hline Total & $\mathbf{1 5 8}$ & $\mathbf{5 2}$ & $\mathbf{2 1 0}$ \\
\hline
\end{tabular}

P- Value $=0.074$.

Table 6: Chi-Square Test Showing the Association between Mothers' Education Level and Measles Immunization in IDPs Camps, Khartoum State, Sudan, 2009

\begin{tabular}{|l|c|c|c|}
\hline \multirow{2}{*}{$\begin{array}{c}\text { Education Level of } \\
\text { the Mother }\end{array}$} & \multicolumn{2}{|c|}{ Immunization of Measles } & \multirow{2}{*}{ Total } \\
\cline { 2 - 3 } & Yes & No & \\
\hline \hline Illiteracy & 59 & 32 & 91 \\
\hline Khalwa & 9 & 0 & 9 \\
\hline Primary & 67 & 17 & 84 \\
\hline Intermediate & 6 & 1 & 7 \\
\hline Secondary & 12 & 1 & 13 \\
\hline University & 5 & 1 & 6 \\
\hline \multicolumn{1}{|c|}{ Total } & $\mathbf{1 5 8}$ & $\mathbf{5 2}$ & $\mathbf{2 1 0}$ \\
\hline
\end{tabular}

P- Value $=0.037$
Table 7: Chi-Square Test Showing the Association between Numbers of Children Under Five Years in the Family and Measles Immunization in IDPs Camps, Khartoum State, Sudan, 2009

\begin{tabular}{|l|c|c|c|}
\hline \multirow{2}{*}{$\begin{array}{c}\text { Number of } \\
\text { Children Under } 5\end{array}$} & \multicolumn{2}{|c|}{ Immunization of Measles } & \multirow{2}{*}{ Total } \\
\cline { 2 - 3 } & Yes & No & \\
\hline \hline Less than 3 & 75 & 32 & 107 \\
\hline $3-5$ & 65 & 16 & 81 \\
\hline Above 5 & 18 & 4 & 22 \\
\hline \multicolumn{1}{|c|}{ Total } & $\mathbf{1 5 8}$ & $\mathbf{5 2}$ & $\mathbf{2 1 0}$ \\
\hline
\end{tabular}

P- Value $=0.037$.

Table 8: Chi-Square Test Showing the Association between Child's Age and Measles Immunization in IDPs Camps, Khartoum State, Sudan, 2009

\begin{tabular}{|l|c|c|c|}
\hline \multirow{2}{*}{ Age of the Children } & \multicolumn{2}{|c|}{ Immunization of Measles } & \multirow{2}{*}{ Total } \\
\cline { 2 - 3 } & Yes & No & \\
\hline \hline $12----15$ month & 41 & 17 & 58 \\
\hline $16-----19 m o n t h$ & 65 & 19 & 84 \\
\hline $20------23$ month & 52 & 16 & 68 \\
\hline Total & $\mathbf{1 5 8}$ & $\mathbf{5 2}$ & $\mathbf{2 1 0}$ \\
\hline
\end{tabular}

P- Value $=0.636$

Table 9: Chi-Square Test Showing the Association between Child's Gender and Measles Immunization in IDPs Camps, Khartoum State, Sudan, 2009

\begin{tabular}{|c|c|c|c|}
\hline \multirow{2}{*}{$\begin{array}{l}\text { Gender of the } \\
\text { Children }\end{array}$} & \multicolumn{2}{|c|}{ Immunization of Measles } & \multirow{2}{*}{ Tota } \\
\hline & Yes & Yes & \\
\hline Male & 84 & 27 & 111 \\
\hline Female & 74 & 25 & 99 \\
\hline Total & 158 & 52 & 210 \\
\hline
\end{tabular}

P- Value $=0.876$.

Table 10: Chi-Square Test Showing the Association between Child's Order in the Family and Measles Immunization in IDPs Camps, Khartoum State, Sudan, 2009

\begin{tabular}{|c|c|c|c|}
\hline \multirow{2}{*}{$\begin{array}{l}\text { Order of the Child } \\
\text { in the Family }\end{array}$} & \multicolumn{2}{|c|}{ Immunization of Measles } & \multirow{2}{*}{ Total } \\
\hline & Yes & No & \\
\hline First & 21 & 10 & 31 \\
\hline Second & 30 & 10 & 40 \\
\hline Third & 41 & 8 & 49 \\
\hline Above four & 66 & 24 & 90 \\
\hline Total & 158 & 52 & 210 \\
\hline
\end{tabular}

P- Value $=0.394$. 


\section{DISCUSSION}

The total number of children screened in this survey was 210 children in IDPs of Khartoum state, which located in three localities. Immunization cards retention among children caretakers were $86 \%$, this means a high documented and verified answer by cards and the rest $14 \%$ verified their immunization status by memory. Our study showed better result than the study done in Ethiopia by Michael in 2000, which showed that the cards retention was $51 \%$ [6]. The total coverage rate of measles vaccination was $75.2 \%$; this was higher than the coverage reported in the ministry of health reports during the last three years especially in 2008 when the coverage was $70.4 \%$. The rest $24.8 \%$ of children are considered as actual unvaccinated children and this could be attributed to the dropout rate of measles, which is high. Most common strategy used for measles vaccination was found to be fixed site strategies, as $92.3 \%$ of children were vaccinated in either health centers or in a hospital, this is the recommended strategy and shows good immunization services. Only $4.4 \%$ are vaccinated by mobile team and $1.3 \%$ by other sources which are mainly acceleration campaign or defaulter follows up vaccination team, this result shows that all type of routine immunization strategies were implemented in the IDPs camps. Our study showed good results compared to a study conducted in 134 camps in March, 2008 by united nation (UN) office of humanitarian in Kenya, which concluded that immunization coverage of measles was very low (43\%) for under five years children [7]. The reason for nonimmunization justified by caretakers includes the followings: Being busy to take their child for vaccination, which constitutes $40.4 \%$ of the caretakers, this was mainly due to economic condition as they have to work to earn their living. One quarter of mothers give no reason for not vaccinating their children due to sickness of the children (9.6\%). In addition to, $9.6 \%$ of mothers did not vaccinate their children because they believe that they have completed the vaccination schedule, this show lack of knowledge about the schedule of immunization. Few percentages of mothers visit the health centre for immunization and did not find vaccine and this is a problem of the supply of vaccine and vaccine management $(5.8 \%)$. Some of mothers believe that their children take too much vaccine and no need for further vaccination $(3.8 \%)$ and this clearly reflects the mothers' attitude toward measles immunization. Few percentage of the mothers blame the fathers of not allowing them to take the children for vaccination
(3.8\%), this also reflects the attitude of fathers and so the community towards measles vaccination, only $1.9 \%$ did not find the vaccinators in the health centre during their visit, this reflects that there were some defect in the monitoring system of the immunization program. Concerning the accessibility of health centers, $67.1 \%$ of mothers live in distance less than $2 \mathrm{~km}$ from the health centers, while $25 \%$ live within the distance less than 5 $\mathrm{km}$, only $7.1 \%$ of mothers live within distance more than $5 \mathrm{~km}$. This shows a good access to the health centers. The same results found when we compare this study with that one conducted in the Khartoum state IDPs camps in 2005, which showed good access to the health centers and low utilization of the services, which was less than $0.3 \%$ [8]. Almost one fifth of mothers believe that their children were healthy and no need for vaccination (19.4\%), $12.9 \%$ of mothers think that their children will get sick after measles vaccination. All of the above reasons reflect the negative attitude of mothers towards measles vaccination. As $83 \%$ of mothers know the measles vaccination this show a good awareness of them compared with a low awareness in the literature. Considerable percentage of mothers know the importance of measles vaccination which show a good attitude toward measles immunization in these camps ( $87.1 \%), 25.9 \%$ believe that the measles will attack the child whether immunized or not, about $22.2 \%$ think that the measles vaccination may causes paralysis, child was sick $3.7 \%$ and other reason was $48.1 \%$. About $66 \%$ of the mothers know the exact age of measles vaccination. As $24.8 \%$ of these children were not vaccinated because of different reasons including that the mother is busy, non availability of the vaccine, the vaccinators were absent, or they went in the wrong date which was not a vaccination day. This reflects that even for those who went for vaccination $34 \%$ came back without doing it. The above reason of no vaccination will lead to high dropout rate which affect the overall coverage and lead to loss of confidence and dissatisfaction of the mothers toward vaccination.

\section{CONCLUSION}

This study reflects not only the coverage rate of measles vaccine among children and the causes behind non-immunization, but also showed the health situation of IDPs and some of the problems facing the displaced population. Some of the main conclusions emerging from the survey findings include the followings: Coverage of measles vaccination among children aged 12-23 months in IDPs of Khartoum state was acceptable. The most common reasons for non- 
immunization were that, caretakers were busy to take their children for vaccination and being unaware of need to return for measles vaccination. Missed opportunities to obtain measles vaccination, were due to, the vaccine was not available or the health workers was absence or the measles vaccine was scheduled in a certain day per week. The mothers' knowledge about measles vaccination and it is importance found to be good. Most of the children in IDPs were vaccinated by fixed sites strategies and the remaining vaccinated by outreach and mobile team. The accessibility to the health center found to be good, but still the utilization of the services is poor. Plan and implement an effective health education programs to increase the awareness of mothers to put the measles vaccination in their priorities. Train the health workers to reduce missed opportunities, provide face-to-face education and give proper appointment for measles vaccination. Maintain enough vaccine supply in the vaccination sites to increase the confidence of mothers toward the program.

\section{ACKNOWLEDGEMENTS}

I would like to express my sincere gratitude and thanks to Dr. Alsadig Mahajoub for his continuous, patient guidance, assistance, and support and expert advices during this study. My great acknowledgement also extended to the Ministry of Health, Khartoum State staff for their support and generous help during this survey.

\section{REFERENCES}

[1] Fact sheet of measles (Rubella, Hard measles, Red measles, Morbilli). (Internet communication, 7 March 2009 at http://www.Who.idph.state.ia.us/adper/common/pdf/epifacts/ measles.pdf).

[2] El-Sayed A. Eltyep highlights on Expanded Program On Immunization (EPI) in Sudan. Sudanese J Public Health 2006; 1: 152-8.

[3] Measles immunization bioline official site 2004. (Internet communication 26 May 2009 at www.bioline.org, br/ request 2004).

[4] Fact sheet of measles December 2008. (Internet communication 8 March 2009 at www.who.int/medictre/fact sheet /fs286/en/index .html dec2008)

[5] World Health Organization, Department of Immunization, Vaccines and Biologicals $\mathrm{CH}-1211$ Geneva 27, Switzerland, immunization coverage cluster survey - reference manual (2005), Geneva, WHO/IVB/04.23.

[6] Michael TK. Factors influencing child immunization coverage in rural district of Ethiopia 2000 (internet communication 30 May 2009 at http //wwwchi-uib.no/Journals/EJHD/ejhdvi7no2/ejhd17n page 105. Pdf).

[7] General-overview of humanitarian aspects in Kenya 2008 (internet communication, 30 May 2009 at www-internaldisplacement.org).

[8] Rapid assessment of health and nutrition in IDPS settlement and peripheral settlement in Khartoum state may 2005. (Internet communication16 May 2009 at www.emro .who, int / sudan / pdf 2006). 